\title{
Barriers leading to treatment default among tuberculosis patients in Khartoum State, Sudan: a qualitative study
}

\author{
Ahmed OAA ${ }^{1 *}$ and Martin HP2 \\ ${ }^{1}$ Ministry of health, Saudi Arabia, PHD Student, Maastricht University Medical Centre, Maastricht, The Netherlands \\ ${ }^{2}$ Maastricht University Medical Centre, Maastricht, The Netherlands
}

\begin{abstract}
Backgrounds: Tuberculosis (TB) is a major public health problem in Sudan and in many African countries. The objective of this study is to provide health authorities and patients with insight into the perceived factors affecting TB treatment default.

Methods: The data was collected by means of focus group discussions (FGD). Six FGD were conducted ( 3 for defaulted patients and 3 for health personnel). Overall, 27 TB defaulted patients and 24 health care providers were randomly selected.

Results: Participants reported that lack of knowledge about TB, high cost of transportation, difficulty for making a daily visit to health facilities for DOT programme due to distance of the facilities from their residences, rural residency, social circumstances, TB-related stigma, lack of family support, patient movement or giving wrong address, seeking traditional healers and treatment-related factors such as side-effects of drugs, the attitude of health care providers, the long delay in obtaining medications, and weakness and challenges facing defaulter tracing teams. There were consistent findings from interviews among patients and health care providers.
\end{abstract}

Conclusions: The study revealed several challenges and barriers leading to TB treatment default. Our findings may help in improving interaction between patients, families, health personnel and policy makers.

\section{Introduction}

Tuberculosis (TB) is a major public health problem in Sudan and in many African countries [1]. In 2010 It was estimated that in Sudan there were 209 cases of active TB per 100.000 of population with an annual incidence of new cases of 119/100.000, resulting in approximately 37.000 new cases each year in Sudan. Hence, Sudan shoulders about $15 \%$ of TB burden in the Eastern Mediterranean Region and has the second highest active $\mathrm{TB}$ prevalence of the countries in this region. In addition, the estimated death rate related to TB, including HIV infected TB patients, was 24/100.000 per year [2].

The TB Control Programme in Khartoum State, Sudan adopted treatment under direct observation short course therapy (DOTS) as recommended by WHO in 1993 [3]. Despite the efforts that had been undertaken by health authorities still some patients fail to adhere to TB treatment and eventually default before completing the intensive stage of treatment. As defined by the WHO, patients who fail to collect their TB treatment for 2 consecutive months are reported as defaulters [4]. The TB Control Programme in Khartoum State estimates the default rate to be more than $14 \%$. This high default rate to TB therapy can prolong infectiousness leading to increased transmission, an increased risk of drug resistance, relapse and death $[5-9,10]$. Thus the identification of risk factors leading to this high TB treatment default rate in Khartoum State is essential.

In general few studies of TB defaulting treatment in Sudan were conducted. These studies dealt only with socio-economic and TB disease related factors leading to TB Treatment default. To our knowledge no study was conducted in Khartoum State, to explore in depth the opinions, experiences and believes of patients and health care providers on TB disease, services and other possible factors associated with TB treatment default.Thus we conducted qualitative study in Khartoum State, to explore the TB patient and health care provider's views about the factors prevent $\mathrm{TB}$ treatment continuation.

\section{Materials and methods}

\section{Setting}

This study was conducted in Khartoum State, the capital city of Sudan. In 1993, the Ministry of Health in Khartoum State established a tuberculosis control program. The decentralized healthcare system in Khartoum is divided into seven districts and 19 health areas. Its health facilities include 43 hospitals, 147 health centers, 185 NGOs centers, 235 dispensaries and 365 primary health care units. TB services are delivered in primary health care along with all other routine health services. A registered nurse is designated responsible for treatment and follow up for continuation of treatment in the primary health care unit. This primary health care unit is the basic unit of management of the program and also the unit of reporting. Personnel at the primary health care unit responsible for tuberculosis services include a medical assistant, a laboratory technician and a clerk. The program provides care through the DOTS strategy (Directly Observed Treatment with Short course chemotherapy) as recommended by WHO. TB patients receive their treatment through $53 \mathrm{~TB}$ treatment units distributed all over the state [11-12].

Correspondence to: Ahmed Osman Ahmed Ali, Ministry of health, Saudi Arabia, Riyadh, Tel: 966508898481; E-mail: abuoosmann@yahoo.com

Received: January 05, 2018; Accepted: January 29, 2018; Published: February 02,2018 


\section{Model of the Study Protocol}

The human of the study were selected from all tuberculosis patients (defaulters and controls) registered at tuberculosis centers and health professionals working in TB treating units in all provinces in Khartoum state from May 2010 to May 2011.A total of six focus group discussions were conducted in large three cities in Khartoum State: Khartoum, Omdurman and Khartoum North to capture believes, culture, geographical and financial differences in various communities. A twenty seven defaulted patient were interviewed in three different focus group discussions (FGD). Each group contained, on average of 8 to 10 participants. In order to further explore the possible leading factors for defaulting we subsequently conducted another 3 (FGD) with a total of 24 health professional representing $53 \mathrm{~TB}$ treatment units in Khartoum State. The inclusion criteria of participants: patients of more than 18 years old and who were receiving treatment for at least one month. Because they were perceived to be more experienced in having $\mathrm{TB}$ and good knowledge regarding tuberculosis treatment barriers.

\section{Data collection}

A qualitative research using the technique of Focus Group Discussion (FGD) methodology was conducting in Khartoum State from May 2010 to May 2011. Data from the participated patients and health care professionals was collected during the period from $1^{\text {st }}$ of May 2011 to $15^{\text {th }}$ of July 2011. A total of six focus group discussions were held. All interviews were performed by the first Author who moderated the discussion in Arabic language. Few days before the FGD discussion the moderator visited the health units to ensure the privacy and logistic arrangement for the comfortable rooms for the these discussions. Also he informed the selected health care professionals telephonically about the study. Each session lasted approximately two and half hours with 20 minutes break in between using structured questionnaire with ended question to collect the necessary information. All interviews took place in privacy rooms and the discussions were recorded on notebook and audiotapes. We ensure that the all participants felt confident and tell reported their pinions freely. Before each FGD session, the moderator welcomed with the participants and explained to them the objectives of the study. The discussion was started with general information then focused on the TB disease, patients knowledge, treatment services, staff receptiveness, health education, the barriers leading to non-adherence and their suggestion to overcome these obstacles. The same questions were covered in each session. This discussion provides an opportunity for more in depth interaction of patients and beliefs about TB disease and reasons leading to treatment default. In addition, it was able the participants to give the insight and ideas on further improvement of the TB compliance. In the interview discussion for the health care professionals we explore their experiences with the barriers leading to TB default and the shortcoming of the medical services at TB units. The recordings were transcribed and translated into English language by the first author.

\section{Data analysis}

After the FGD sessions, all recordings of data from defaults patient's interviews and data from health care professional's interviews were transcribed verbatim and translated into English language. Then the data were summarized, coding and analysis was done based on the theme arising from the data. The analysis of data including the patient's perception about TB disease, the treatment services, patient knowledge, family and community supports, staff receptiveness, barriers leading to default and their suggestions to overcome these barriers. Also the data from health professionals interviews were coded and analyzed using the same contents theme. After coding, the grouping, condensing, categorizing and summarizing of these data were done. The findings of the in-depth interviews and FGD described the possible barriers leading to TB default were concluded and reported in the results section below.

\section{Ethical considerations}

Ethical approval was obtained from Ministry of Health Khartoum State, Ethical Committee. Informed verbal consent was secured from every eligible patient and health care provider included in this study before the interview. Privacy and confidentially was maintained. The participants had been informed regarding all relevant aspects of the study, including the purpose of the study, the process of FGD and potential benefits. The participants in all 6 FGD felt confident and happy to be involved in this discussion and were speaking freely.

\section{Results}

\section{The characteristics of participants}

Six sessions of focus group discussion (FGD) were conducted to investigate the factors influencing non adherence to TB treatment. Three sessions were targeted at TB default patients while the other 3 sessions involved health care providers. The sessions aimed to address related experiences of stakeholders participated in TB treatment. The participating defaulted patients were made up of 21 males and 6 females. The mean age and standard deviation (SD) of patients were 36.2 and 8.1 respectively. All respondents were Muslims, with the majority came from urban area $(74.1 \%)$ and almost all were of low socioeconomic status. six doctors, and 18 nurses participated in the interviews with mean age and SD of 37.7 and 7.6 respectively. The health care professionals interviewed were mainly from urban areas $(75 \%)$ and majority of them had worked in primary health care centers (79.2\%). About Fifty four percent of them had long working experiences with TB control programme in Khartoum state compared to only (16.7\%) with less than 10 years of working experiences. All of them worked in various health care facilities including health centers and hospitals, (Tables 1 and 2).

\section{The results of interviews}

The relatives variables identified from the results analysis can be categorized in five large groups: patients' knowledge about TB disease; behaviour related factors including traditions and norms;

Table 1. The characteristics of participants (patients)

\begin{tabular}{|l|l|}
\hline Variables & $\begin{array}{l}\text { FGD (defaulted patients(27) } \\
\text { Total }(\mathbf{n}=\mathbf{2 7}) \mathbf{n}(\mathbf{\%})\end{array}$ \\
\hline $\begin{array}{l}\text { Age } \\
\text { Between 15 and 30 years } \\
\text { Over 30 years }\end{array}$ & $5(18.5)$ \\
\hline $\begin{array}{l}\text { Sex } \\
\text { Male }\end{array}$ & $22(81.5)$ \\
Female & $21(77.8)$ \\
\hline Education & $6(22.2)$ \\
Illiterate & \\
Literate & $17(63)$ \\
\hline Residence & $10(37)$ \\
Urban & \\
Rural & $7(25.9)$ \\
\hline Marital status & $20(74.1)$ \\
Married & \\
Single & $11(40.7)$ \\
Others (divorced, widow) & $15(55.6)$ \\
\hline Occupation & $1(3.7)$ \\
\hline Had no job & \\
Had a job & $12(44.4)$ \\
\hline
\end{tabular}


Table 2. The characteristics of participants (health care providers).

\begin{tabular}{|c|c|}
\hline Variables & $\begin{array}{l}\text { FGD health care professionals }(24) \\
\text { Total }(n=24) n(\%)\end{array}$ \\
\hline $\begin{array}{l}\text { Age } \\
\text { Between } 15 \text { and } 30 \text { years } \\
\text { Over } 30 \text { years }\end{array}$ & $\begin{array}{l}4(16.7) \\
20(83.3)\end{array}$ \\
\hline $\begin{array}{l}\text { Sex } \\
\text { Male } \\
\text { Female }\end{array}$ & $\begin{array}{l}19(79.2) \\
5(20.8)\end{array}$ \\
\hline $\begin{array}{l}\text { Occupation } \\
\text { Doctor general practitioner } \\
\text { Nurse(6) and medical assistant(11) }\end{array}$ & $\begin{array}{l}6(25.0) \\
18(75.0)\end{array}$ \\
\hline $\begin{array}{l}\text { Experience in TB management and follow } \\
\text { up } \\
\text { More than } 20 \text { years } \\
10 \text {-20years } \\
\text { Less than } 10 \text { years(the minimum } \\
\text { experience is } 7 \text { years) }\end{array}$ & $\begin{array}{l}13(54.1) \\
7(29.2) \\
4(16.7)\end{array}$ \\
\hline $\begin{array}{l}\text { Place of working } \\
\text { Specialized hospital( } 2 \text { hospitals }) \\
\text { Health centers }\end{array}$ & $\begin{array}{l}5(3 \text { doctors and } 2 \text { nurses })(20.8) \\
19(3 \text { doctors, } 4 \text { nurses } 11 \text { medical officers }) \\
(79.2)\end{array}$ \\
\hline $\begin{array}{l}\text { Area of working } \\
\text { Urban } \\
\text { Rural }\end{array}$ & $\begin{array}{l}18(75) \\
6(25)\end{array}$ \\
\hline
\end{tabular}

socio demographic factors; the health services including the health care providers' attitude and treatment related factors and believe in traditional healers and their methods.

\section{Patient's knowledge about TB disease}

The results analysis of interviews of FGD revealed that most of the patients had known TB disease, either from family members, relatives or lived with a contact (someone who has TB). Even though, most of TB defaulted patients were aware that TB is a serious disease, more than $60 \%$ of them had limited information about the causes of disease, clinical presentation and mode of transmission. These results were confirmed by health care providers (about $66.7 \%$ of TB default patients had lack of knowledge). The possible causes of TB mentioned by respondents included: TB is an inherited, drinking cold water, witchcraft, and heavy works such as making bricks. However, 2 of them mentioned that TB is caused by germs.

The participants listed various symptoms and signs of TB including: dry cough, fever, tiredness, and back pain. Almost all the interviewed TB patients reported that they presented to the health centers with productive cough, fever, weakness, anorexia, and or shortness of breath. However, around $40 \%$ of them explained that they didn't know about TB before having it Tables 1,3 and 4 .

I heard about TB from my eldest brother, when he had infected with TB 6 years ago (39 years old illiterate man).

\section{I did not know about TB before I had it (35 years old women).}

The TB disease can be transmitted by shaking hand with an infected person (male opinion).

My father told me that I got TB since I was a child, my grandmother had similar symptoms, it is in our lineage inherited (female opinion).

TB got me because I worked hard, Iam a farmer (male opinion)

We got TB from cold drink, we used to drink cold water in the market especially during summer seasons, and it was very serious (4 male participants).

Similar results were mentioned by health care providers, (during my practical experience for more than 20 years working in TB programme in various health units and the last 6 years in this hospital, I had met a good number of TB patients who came seeking medical advice who lacked knowledge of the TB disease including causes, mode of transmission, clinical presentation, and treatment. Among patients I met, some preferred seeking treatment from traditional healers. (One medical practitioner doctor).

\section{The behavioural and socio demographic factors}

The analysis of FGDs revealed that the most social factors leading to default TB treatment were financial (low family income $(81.5 \%)$, had no job (55.6), the transportation cost (77.8\%) and cost of drugs), distant health unit (70.4\%) and lack of family support (70.4\%). All FGD endorsed the financial burden as the strongest factor affecting access and patients' adherence to treatment. The participants mentioned that although, the treatment services were offered free of charge by the state TB program, still some patients may face obstacles of accessing this free services; such as far distances, cost of transportation in addition to other social reasons such as the fact that women in some rural communities need to be escorted to the health unit. The interviewee said these obstacles may force some of them to buy their medication

Table 3. The barriers leading to TB treatment default according to health care professionals FGD.

\begin{tabular}{|c|c|}
\hline The factors & $\begin{array}{l}\text { Opinions of health care professionals } \\
\text { Total }(n=24) n(\%)\end{array}$ \\
\hline $\begin{array}{l}\text { Site of tuberculosis } \\
\text { Pulmonary } \\
\text { Extra-pulmonary }\end{array}$ & $24(100)$ \\
\hline $\begin{array}{l}\text { Type of residential area } \\
\text { City } \\
\text { Village }\end{array}$ & $\begin{array}{l}6(25) \\
18(75)\end{array}$ \\
\hline $\begin{array}{l}\text { Distance to clinic } \\
\text { Between } 1 \text { and } 5 \text { kilometers } \\
\text { More than } 5 \text { kilometers }\end{array}$ & $\begin{array}{l}4(16.7) \\
20(83.3)\end{array}$ \\
\hline $\begin{array}{l}\text { Patient moving or giving wrong address } \\
\text { Yes } \\
\text { No }\end{array}$ & $\begin{array}{l}4(16.7) \\
20(83.3)\end{array}$ \\
\hline $\begin{array}{l}\text { Transportation cost } \\
\text { Less than } 3 \text { Sudanese pound(SD) } \\
3 \text { Sudanese pound(SD) or more }\end{array}$ & $\begin{array}{l}8(33.3) \\
16(66.7)\end{array}$ \\
\hline $\begin{array}{l}\text { Time to clinic } \\
\text { Up to } 60 \text { minutes } \\
\text { More than } 60 \text { minutes }\end{array}$ & $\begin{array}{l}11(45.8) \\
13(54.2)\end{array}$ \\
\hline $\begin{array}{l}\text { Family income }=(\text { mean }, S D) \\
\text { Less than } 1000 \text { Sudanese pound(SP) } \\
\text { More than } 1000(S P)\end{array}$ & $24(100)$ \\
\hline $\begin{array}{l}\text { Family support } \\
\text { those with family support } \\
\text { those without family support }\end{array}$ & $24(100)$ \\
\hline $\begin{array}{l}\text { Patient's knowledge } \\
\text { Good knowledge } \\
\text { Little knowledge }\end{array}$ & $\begin{array}{l}8(33.3) \\
16(66.7)\end{array}$ \\
\hline $\begin{array}{l}\text { Response to treatment } \\
\text { Good } \\
\text { Not good }\end{array}$ & $24(100)$ \\
\hline $\begin{array}{l}\text { Side effects to TB treatment } \\
\text { Had side effects } \\
\text { No side effects }\end{array}$ & $\begin{array}{l}6(25) \\
18(75)\end{array}$ \\
\hline $\begin{array}{l}\text { Try to hide that had TB disease(stigma) } \\
\text { Yes } \\
\text { No }\end{array}$ & $\begin{array}{l}13(54.2) \\
13(45.8)\end{array}$ \\
\hline $\begin{array}{l}\text { DOTS } \\
\text { Those on Dots vs } \\
\text { Not DOTS }\end{array}$ & $24(100)$ \\
\hline $\begin{array}{l}\text { Seek folk remedies } \\
\text { Yes } \\
\text { No }\end{array}$ & $24(100)$ \\
\hline Health care provider approach & $24(100)$ \\
\hline
\end{tabular}


Table 4. The barriers leading to TB treatment default according to patients.

\begin{tabular}{|c|c|c|}
\hline The factors & $\begin{array}{l}\text { defaulted patients } \\
\text { Total }(n=27) \text { n }(\%)\end{array}$ & $\begin{array}{l}\text { adherence patients Total (n } \\
=9) \mathrm{n}(\%)\end{array}$ \\
\hline $\begin{array}{l}\text { Site of tuberculosis } \\
\text { Pulmonary } \\
\text { Extra-pulmonary }\end{array}$ & $\begin{array}{l}25(92.6) \\
2(7.4)\end{array}$ & $\begin{array}{l}7(77.8) \\
2(22.2)\end{array}$ \\
\hline $\begin{array}{l}\text { Type of residential area } \\
\text { City } \\
\text { Village }\end{array}$ & $\begin{array}{l}20(74.1) \\
7(25.9)\end{array}$ & $\begin{array}{l}8(88.9) \\
1(11.1)\end{array}$ \\
\hline $\begin{array}{l}\text { Distance to clinic } \\
\text { Between } 1 \text { and } 5 \text { kilometers } \\
\text { More than } 5 \text { kilometers }\end{array}$ & $\begin{array}{l}8(29.6) \\
19(70.4)\end{array}$ & $\begin{array}{l}6(66.7) \\
3(33.3)\end{array}$ \\
\hline $\begin{array}{l}\text { Patient moving or giving } \\
\text { wrong address } \\
\text { Yes } \\
\text { No }\end{array}$ & $\begin{array}{l}10(37.0) \\
17(63.0)\end{array}$ & $\begin{array}{l}7(77.8) \\
2(22.2)\end{array}$ \\
\hline $\begin{array}{l}\text { Transportation cost } \\
\text { Less than } 3 \text { Sudanese } \\
\text { pound(SD) } \\
3 \text { Sudanese pound(SD) or } \\
\text { more }\end{array}$ & $\begin{array}{l}6(22.2) \\
21(77.8)\end{array}$ & $\begin{array}{l}5(55.5) \\
4(44.5)\end{array}$ \\
\hline $\begin{array}{l}\text { Time to clinic } \\
\text { Up to } 60 \text { minutes } \\
\text { More than } 60 \text { minutes }\end{array}$ & $\begin{array}{l}12(44.4) \\
15(55.6)\end{array}$ & $\begin{array}{l}7(77.8) \\
2(22.2)\end{array}$ \\
\hline $\begin{array}{l}\text { Family income }=(\text { mean, } S D) \\
\text { Less than } 1000 \text { Sudanese } \\
\text { pound(SP) } \\
\text { More than } 1000(\mathrm{SP})\end{array}$ & $\begin{array}{l}22(81.5) \\
5(18.5)\end{array}$ & $\begin{array}{l}5(55.5) \\
4(44.5)\end{array}$ \\
\hline $\begin{array}{l}\text { Family support } \\
\text { those with family support } \\
\text { those without family support }\end{array}$ & $\begin{array}{l}8(29.6) \\
19(70.4)\end{array}$ & $\begin{array}{l}8(88.9) \\
1(11.1)\end{array}$ \\
\hline $\begin{array}{l}\text { Patient's knowledge } \\
\text { Good knowledge } \\
\text { Little knowledge }\end{array}$ & $\begin{array}{l}10(37.0) \\
17(63.0)\end{array}$ & $\begin{array}{l}5(55.5) \\
4(44.5)\end{array}$ \\
\hline $\begin{array}{l}\text { Presenting symptoms to the } \\
\text { clinics(productive cough, } \\
\text { fever, weakness, anorexia, } \\
\text { and or shortness of breath) } \\
\text { Yes } \\
\text { No }\end{array}$ & $\begin{array}{l}27(100.00) \\
0(0.00)\end{array}$ & $\begin{array}{l}9(100.00) \\
0 .(0.00)\end{array}$ \\
\hline $\begin{array}{l}\text { Response to treatment } \\
\text { Good } \\
\text { Not good }\end{array}$ & $\begin{array}{l}16(59.3) \\
11(40.7)\end{array}$ & $9(100)$ \\
\hline $\begin{array}{l}\text { Side effects to TB treatment } \\
\text { Had side effects } \\
\text { No side effects }\end{array}$ & $\begin{array}{l}21(77.8) \\
6(22.2)\end{array}$ & $\begin{array}{l}1(11.1) \\
8(88.9)\end{array}$ \\
\hline $\begin{array}{l}\text { DOTS } \\
\text { Those on Dots vs } \\
\text { Not DOTS }\end{array}$ & $\begin{array}{l}10(37.0) \\
17(63.0)\end{array}$ & $\begin{array}{l}8(88.9) \\
1(11.1)\end{array}$ \\
\hline $\begin{array}{l}\text { Try to hide that had TB } \\
\text { disease(stigma) } \\
\text { Yes } \\
\text { No }\end{array}$ & $\begin{array}{l}10(37.0) \\
17(63.0)\end{array}$ & $\begin{array}{l}0(0.00) \\
9(100)\end{array}$ \\
\hline $\begin{array}{l}\text { Seek folk remedies } \\
\text { Yes } \\
\text { No }\end{array}$ & $\begin{array}{l}10(37.0) \\
17(63.0)\end{array}$ & $\begin{array}{l}8(88.9) \\
1(11.1)\end{array}$ \\
\hline $\begin{array}{l}\text { Health care providers } \\
\text { approach } \\
\text { Receptive } \\
\text { Non receptive }\end{array}$ & $\begin{array}{l}5(18.5) \\
22(81.5)\end{array}$ & $\begin{array}{l}7(77.8) \\
2(22.2)\end{array}$ \\
\hline
\end{tabular}

for one or two months only from any near private health facilities. Thus the social and financial factors significantly affected treatment seeking behavior: they find it much easier to seek care from traditional healers than going to a distant public health care facility especially in rural areas and among illiterate patients (63\%). Cost of drugs, consultation, and hospital admission were identified as key barriers by some respondents. In addition to of accommodation and living expenses, as well as the risk of losing job Tables 1, 3and 4. Similar reasons were revealed from the analysis of health care providers' discussions.
I faced a very embarrassing situation, that I had no money. Frankly speaking, how will we survive if we have no money in our hands, no treatment, no transportation, no food and without job (one male opinion)

To collect my free medication from the health unit, I had to travel for 2 hours daily, specially during the first 2 months and I needed a companion to go with me, also I have to stay for more than an hour to collect the medication. The cost of transportation is more than 20 Sudanese pounds; my husband told me that he cannot afford this. Then he brought a herbal medication from his friends (41 years old, one woman).

\section{Distance and travelling cost}

A group of participants stated that the challenge for TB patients is geographical distance and they had to come on daily basis to take their medication under direct supervision at health center., These challenges faced mainly those lived in rural communities or those who lived far from the health center. The health care professional mentioned the relation of distance (83.3\%), and transportation cost $(66.7 \%)$ to treatment default.

\section{Patient movement or changing address}

About $63 \%$ of participant mentioned that they moved or changed address during $\mathrm{TB}$ treatment duration which was confirmed by the health care providers. In addition, $(83.3 \%)$ of health care providers stated that wrong address or incomplete information and patient movement were associated factors for non adherence to treatment..

(From my experience, I would like to tell this story, one day I went to trace a defaulted patient, I took his address from patient records, I found that he was shifted to another house not far from here. The patient mentioned that the main reason to discontinue his treatment because he felt better after one month of starting treatment, and he must look for a job to provide his family with daily living expenses as there was no body to help him. Now he used herbal remedies brought from a traditional healer(30 years one medical assistant in a health center).

\section{Lack of family support and stigma}

The participants discussed that patients with TB disease need family and community support (financial, psychological and moral support) to adhere to treatment especially during the first two months. Some patients mentioned that sometimes they felt guilty as this will affect their family income especially if a family member left his work to accompany him to the health unit.

(the family support is important factor to continue the treatment, I faced stress from my brothers. This discourage me from taking drugs) (one female opinion).

Many patients believed that they were predisposed to stigma (63\%) because of TB. These believes prevented them to attend social events and occasions. (My relatives and friends believed that I was infectious, as I had TB disease, and they tried to avoid me. (one male opinion).

Other respondents stated that no significant changes in the behavior of peoples towards them, no precautions were taken against them, and social support of family and friends was continued as normal which helped them taking treatment.The health care professional emphasized that TB patients feel stigmatized by closed relatives or friends due lack of knowledge about TB in the community. This encouraged some patients to hide that they had TB even form their spouses. (TB may affect patient interaction with others, specially females could not get 
married as she had TB disease( 2 males, health care providers).These circumstances may lead patients to delay seeking treatment. (I got TB few months ago, I did not tell anybody, even my family member, TB was infectious disease, nobody will respect me and all will try to avoid me(one male opinion). Other few participants stated that they told their families and close friends about TB infection, they provided them support and encouragement during the treatment duration. (I accept that I got TB infection, without complain, I told my family and old friends, about my $T B$ infection. They told me to be strong, TB is a curable disease, we pray for you and ask god to bless you.(one male opinion).

Some health care providers mentioned that till now there are separate clinics in some health centers for treating TB patients, this make them feel stigmatized.

\section{Health services, treatment related factors and attitude of health care providers}

There were divergent views among patients regarding the barriers leading to $\mathrm{TB}$ default, especially the health services and treatment related factors (side effect of drugs, barriers related to health center for DOTS programme, and health professional attitude).

\section{The treatment factors}

About $63 \%$ of defaulted patients were not on DOTS programme. They mentioned that DOTS with daily supervision of treatment for the first two months (initial phase) was a challenge to them especially during this phase. During the initial phase many patients were ill, weak and suffered from the severity of the disease. This meant that they needed to visit the TB clinic with a family member. Thus not merely the patients bearing the burden of TB, but involved their families and relatives.

"I had to come every day for injections and to swallow the medication in front of the nurse. I came daily with my brother because Iam ill, I tell you the truth, we had to hurry to reach here early in the morning, sometimes without even having breakfast. We cannot afford to come every day. It was very difficult to me and my family. In addition, we sold all properties, now we need financial support but no body to help us, so how can we continue the treatment for 2months?" (41 year-old female":

The DOTS programme was compounded by several challenges: geographical distance, transportation cost and daily attendance, especially for women and those coming from rural areas. Those who had no cars used public transportation, bicycles, riding camels and donkey or even o on foot.

I had to wake up early at 5:30 A.M every day to catch a car to travel for more than $25 \mathrm{KM}$ to the health unit and then returning back home. I was asked to continue treatment for 2 months. If there was a rain I had to stay with my relative in Khartoum North. The transportation cost me a lot. All this cost provided from my relatives as I had no job during this period. Also the far distance made me uncomfortable, and sweat a lot, in addition, the dust and smoke exhausted by the car made us feel dirty . I tried this for a month before deciding to discontinue the treatment, especially after I felt better. (39 male patient from a rural area).

The health care providers expressed their well awareness of TB treatment and emphasized the availability of health services at DOTS health centers. At the same time they admitted the shortage of health staff, and lack of training. All health care providers stated that DOTS programme is an important factor for treatment adherence and cure. However, some reported that coming daily to the TB clinic especially in the intensive phase of treatment was physically and financially demanding for sick patients.. (from my experience, seeking medical treatment is related to the patients knowledge, as treatment of TB may continue for more than 6months, this needs commitment. DOTS programme helps patients to continue their treatment, offers opportunity for interaction between patients and health personnel, to increased their information. But still coming on daily bases was difficult for sick, poor patients, and those coming from far. Thus some patients may discontinue treatment after short period, especially when he feels better or finds alternative treatment. (one male health care provider)

(Some patients seek medical advice too late, one day We got a very sick patient, he was diagnosed with TB. He told me that he thought that it was a normal cough, although he complained of it for more than 6 weeks. (one male medical doctor)

\section{Side effects to treatment}

More than $77 \%$ of defaulted patients experienced side effects to TB medication and mentioned the burden of TB drugs and their side effects being the major challenges on concomitant treatment. The main side effects noted by the patients and health care providers included headache, rash, nightmares, burning abdomen, feeling of hunger, vomiting and generalized body weakness.

Since I have started to swallow tablets and to be injected on daily basis, my body was harmed. Few days later I developed itching, hungry and burning abdomen. I mentioned this to the nurse. He said to me these symptoms will subside and gave me another medication but the side effects never subsided. When I told the nurse that I still suffer from the same side effects, he always retort and did not believe what I said, and considered me as annoying patient. Then I decided to discontinue treatment(44 years male). These results were reinforced by 6 health care providers.

Other health care providers reported that some patients seek medical treatment when they feel ill, and stop treatment when feeling better. Additionally, they mentioned that medications side effect were a leading cause of default(75\%).

\section{The attitude of health care providers}

The majority of defaulted patients in the study were not happy about attitude and approach of health professionals(81.5\%). The participants mentioned that the health care provider should be receptive, friendly, follow a warm approach when educating patients. The health care provider mentioned that their main roles are diagnosis and treatment of the disease, but also they used to provide their patients with some information on TB disease. All of them followed friendly approach with patients and increased interaction with them to enhance continuation of treatment. They all emphasized the importance of having a health educators at each health unit.

I visited the health unit many time: at the first visit they told me that I have a chest infection. After 15 days I came back with the same symptoms and then referred me to the TB unit. They told me that I had $T B$ disease. The nurse asked me to come tomorrow for treatment. When I came next day I stayed for more than 1 hour, after that the nurse called me, please come in, today you will start TB treatment. He didn't give me enough information about the disease and its treatment, he seemed to be in hurry to finish this visit as if he afraid to catch this disease and avoid sitting beside me. This approach embarrassed me and I felt this disease as stigma in the community. (48 years women).

The health care providers mentioned that they try to support their patients and families but still some patients cannot accept their 
infection with TB and may hide it even from their close relatives, and eventually discontinue the treatment.

\section{The TB treatment default tracing team}

A key barriers raised during the interviews discussion by a proportion of patients and the health care providers was the weakness of defaulters tracing team-. Interestingly, this factor had not been included in the questions asked by the moderator. Some patients mentioned they discontinued the treatment for months and had not been called or visited by the health professional, while few patients mentioned that had received calls from the health units. One patient said he had been visited once by his treating nurse, he explained that his house lie near to the health unit, also he had a friendship with this nurse.

The health care providers mentioned that the TB control programme had problems in tracing TB defaulters. This was attributed to shortage of staff, lack of transportation and communication means, incomplete patients address information and staff related difficulty such as female health professionals inability to trace defaulted patient due to cultural factors. (we feel and know the importance of communication with our patients, the tracing of defaulted patients, but how can we achieve this? There was no default tracing team at the health unit, no car or any mean of transportation, sometimes had no means of communication with these patients, either due to wrong or incomplete address for the patients or the telephone at health center was out of service(44 years male nurse).

"how can I visit the patient's home, Iam a female and my husband cannot accept that (32years female nurse).

\section{Traditional healers}

About $63 \%$ of defaulted TB patients admitted that according to their culture and norms, going to the traditional healers or taking herbal drugs was preferable to visiting health centers. As per patients and health care providers, other reasons for seeking traditional healing were: lack of knowledge, cost of travelling, daily collection of medication, misbelieves about, lack of social support, waiting time at health facility, health care providers attitude, stigma, high expectation of immediate healing and improvement, medications' Side effects, injectable treatment, and duration of treatment.

(I preferred to go take herbal treatment as the traditional healer was more friendly and well known to me, and I trust him as well (one female patient).

(I got a cough for 4 weeks, I had to wake up early to visit a far health center, it costed me more than 30 pounds daily for transportation and breakfast. After one week my elder brother asked me to go with him to a famous traditional healer, who claimed to be having long experience in treating many diseases. He was a simple man, friending had a good sense of humor, accept any amount of money and even other gifts. He prepared for me herbal medicine. (one man opinion).

(Illiterate, Poor patients cannot afford treatment completion regardless the source of the treatment (one male, health care provider).

(The norms and traditional in our community had negative impact on TB treatment, some patients started treatment at the health unit, few days may go to seek other advice either from private sectors or go to traditional healers. Therefore, health education, and involvement of community organizations is mandatory to increase awareness of patients, and their families about TB disease and the treatment compliance. One male medical doctors)
The traditional healer in our village was friendly, gave drug with little money, no waiting time, no cost of travelling, (one male patient).

\section{Discussion}

The present qualitative study revealed five major factors that most $\mathrm{TB}$ treatment defaulting patients mentioned when assessing the TB services offered by the TB Control Programme in Khartoum State. These factors were: 1) patients' knowledge about the disease TB; 2) behavior related factors that included traditions and norms; 3 ) sociodemographic factors, especially income versus cost and distances to the TB center; 4) the health services provided itself, including the health care providers attitude and treatment related factors and; 5) believe in traditional healers and their methods. These factors represent opinions of three samples of TB treatment defaulting patients and three samples of health care providers who worked for a long period in TB units in Khartoum State.

The barriers reported by TB treatment defaulting patients and health care providers who participated in this study were not well known and not familiar to both the Khartoum community and the policy makers of the TB control program in Khartoum state, although they were reported previously in many international studies [3,13-15]. In addition, this the first larger qualitative wide study that explored the opinions and experiences of the patients and treating staff themselves about the barriers related to interruption of TB treatment. Moreover, the results highlight the attitude of health care workers towards the patients, patients knowledge about TB disease and its treatment, the economic effects, including cost of travelling, food and loss of work and the believe in traditional healers. Interestingly, there was another barrier raised by the participants in the six focus group discussions, i.e. the poor availability of communication and transportation for the treatment default tracing team.

$\mathrm{TB}$ is a disease prevalent among poor communities and when diagnosed needs continuous treatment for at least 6 months [16]. This means that patients on a DOTS program will need to come on daily basis to take their treatment in presence of the nursing staff at the TB clinic. This create challenges, identified in this study, including the cost of travelling, especially for those who lived in rural areas. Another barrier, reported by the participants concerned especially females who, as necessitated by the traditions and norms of the Khartoum society, need companion to visit the TB units. Our findings consolidate the previous results in the developing and developed countries [5,1720]. The patients tried to overcome these challenges by seeking help from their relatives and non-governmental charity organizations. Although the TB services are offered on free base to all patients, these still barriers to the accessibility and acceptability to these services. One way to improve accessibility could be the integration of TB services in the primary health care centers scattered all over the state. The absence of specialized knowledge on diagnosis and treatment of TB could be amended be e.g. weekly visits of a TB center specialist. In addition, it would be important to further study and measure patient satisfaction with the TB services that includes their and their relative's opinion regarding the DOTS program. For example those who live far from the TB units may take their treatment under supervision of one their family members, with e.g. a confirmatory texting message.

$\mathrm{TB}$ is a familiar disease worldwide, nevertheless, a large number of patients lack knowledge about the disease. This due to illiteracy, and the insufficient education and counseling given to the patients. Also we observed that patients seeking treatment from traditional healers are more likely to default their TB treatment. These findings are similar to 
results of other studies in developing countries with low resources in Africa and Asia which carry the highest burden of TB [13,18, 21-23].

We found that the patient's perception regarding the health care provider attitude is an important determinant factor for adherence to TB treatment. However, the health provider attributed the influence of this factor to shortage of staff and high work load, lack of health education given to the patients, and self-stigmatization among patients. Therefore we recommend that health personnel to follow a warm approach with their patients and assure them that TB is curable. This approach will create good rapport between health providers and their patients. Hence, encourage patients adherence to treatment. These findings are in line with results reported by other studies $[3,13,15,21$ $22,24]$. Although our findings in contrast with that mentioned by Nyi form Malaysia [25] and Ayé from Tajikistan [4].

This study confirmed that waiting time, side effect of treatment and patient movement are associated with TB defaults. These findings match previous studies in developed and developing countries [3, 10,12,13]. Although our findings are in contrast with that reported by Nyi [25].

Although the intention of the National TB Control Programme was to have an effective tracing team, the interesting barrier related to treatment default which raised by most of the participants in this study was the weakness of TB default tracing team. This needs special attention and deserve an assessment of TB control programme. This weakness was attributed to shortage of staff, lack of transportation and communication means and cultural barriers. These findings in line with the result reported by other international studies (south Africa) [26].

The findings of this study might help the policy makers in Khartoum state, Sudan and other developing countries in planning and policy development to strengthen TB control programs in general. Moreover the barriers need special attention including: health education, travel cost, family support, waiting time, patients movement, traditional healers, staff receptiveness. It needs the cooperation of the community members, patients, families, treating staff, and governmental and nongovernmental organizations. These efforts may help patients socially and financially. These will help strengthening interaction between the patients, their families and treatment staff. In addition, more attention should be paid to staff training, regarding the health education, supervision and receptiveness.

Overall the findings of present study raise important issues on $\mathrm{TB}$ treatment default in Sudan since we could not identify previous detailed studies on this subject in this area. These results can help in decreasing the TB treatment default. Thus, decreasing treatment failure, multi drugs resistant, $\mathrm{TB}$ relapse and inhibit spreading of tuberculosis in the community.

Some methodological aspects of this study need attention: First, the major problem we faced during the study was how to reach the defaulting patients. This problem was tackled in 3 steps. First, the patient medical records were traced and identified and all contact information was reviewed. Then, study personnel first tried to telephone the patient and, failing that, to telephone known family members or friends. If telephone contact failed or if there was no telephone number on record, home visits were made, first to the patient and then to known family members or friends. Secondly, this study was qualitative study which help in identifying the perception, opinions and problems of different patients and health care providers. Thirdly, the qualitative study may help in improving the treatment and strengthening the TB control programme. Fourthly, the results of focus group discussion included the patients opinions and the long experience of health care providers.
Lastly, to reduce the recall bias, we interviewed three groups of patients who were recently defaulted and came back in addition to interviewing health staff who had long working experiences.

\section{Conclusion}

The study highlighted several challenges and barriers leading to TB treatment default. Our findings may help the interaction between patients, families, health personnel and policy makers. We believe that the findings are applicable to current situation of TB management and control in Sudan and other developing countries.

\section{Disclosure statement}

The authors declare that there is no conflict of interest or funding received regarding the publication of this paper.

\section{References}

1. WHO (2015) Global tuberculosis report. 20th Ed. Geneva.

2. Federal Ministry of Health (2011) General Directorate of Primary Health Care. Sudan: National Tuberculosis Control Programme

3. Muture B, Keraka M, Kimuu P, Kabiru E, Ombeka V, et al. (2011) Factors associated with default from treatment among tuberculosis patients in Nairobi province, Kenya: A case control study. BMC Public Health 11:1-10. [Crossref]

4. WHO (2002) Operational guide for national tuberculosis control programmes on the introduction and use of fixed-dose combination drugs. Geneva.

5. Chuah SY (1991) Factors associated with poor patient compliance with antituberculosis therapy in Northwest Perak, Malaysia. Tubercle 72: 261-4. [Crossref]

6. Menzies R, Rocher I, Vissandjee B (1993) Factors associated with compliance in treatment of tuberculosis. Tuber Lung Dis 74: 32-37. [Crossref]

7. Wilkinson D (1994) High-compliance tuberculosis treatment programme in a rural community. Lancet 343: 647. [Crossref]

8. William JB, Cohn DL, Rietmeijer CA, Judson FN, Sbarbaro JA, et al. (1997) Noncompliance with directly observed therapy for tuberculosis: epidemiology and effect on the outcome of treatment. Chest 111:1168-1173. [Crossref]

9. Jasmer RM, Seaman CB, Gonzalez LC, Kawamura LM, Osmond DH, et al. (2004) Tuberculosis treatment outcomes: directly observed therapy compared with selfadministered therapy. Am J Respir Crit Care Med 170: 561-566. [Crossref]

10. Ahmed OA Ali, Martin HP (2017) Disease and treatment-related factors associated with tuberculosis treatment default in Khartoum State,Sudan: a case-control study. East Mediterr Health J 23: 346-352. [Crossref]

11. Ahmed Suleiman MM, Aro AR, Sodemann M (2009) Evaluation of tuberculosis control programme in Khartoum State for the year 2006. Scand J Public Health 37: 101-108. [Crossref]

12. Ali AOA, Prins HM (2016) Patient non adherence to tuberculosis treatment in Sudan socio-demographic factors influencing non adherence to tuberculosis therapy in Khartoum State. Pan Afr Med J. 25: 80 [Crossref]

13. Elbireer S, Guwatudde D, Mudiope P, Sekandi,JN, Manabe YC (2011) Tuberculosis treatment default among HIV-TB co-infected patients in urban Uganda. Trop Med Int Health 16: 981-987. [Crossref]

14. Ayé R, Kaspar Wyss K, Abdualimova H, Saidaliev S (2010) Illness costs to households are a key barrier to access diagnostic and treatment services for tuberculosis in Tajikistan. BMC Res Notes 3: 340. [Crossref]

15. Sanou A, Dembele M, Theobald S, Macq J (2004) Access and adhering to tuberculosis treatment: Barriers faced by patients and communities in Burkina Faso. Int $J$ Tuberc Lung Dis 8: 1479-1483. [Crossref]

16. Sharma SK, Mohanan S, Sharma A (2012) Relevance of latent TB infection in areas of high TB prevalence. Chest 142: 761-773. [Crossref]

17. Ibrahim LM, Hadejia IS, Nguku P, Lakda GM, Ogiri S, et al. (2015) Factors Associated with Outcomes of Treatment among Pulmonary Tuberculosis Patients in Plateau State, Nigeria. J US China Med Sci. 12: 172-179.

18. Ayisi JG, Hoog AH, Agaya JA, Mchembere W, Odylia M et al. (2011) Care seeking and attitudes towards treatment compliance by newly enrolled tuberculosis patients in the district treatment programme in rural western Kenya: a qualitative study. BMC Public Health 11: 515. 
19. Sagbakken M, Frich JC, Bjune GA, Porter JDH (2013) Ethical aspects of directly observed treatment for tuberculosis: a cross-cultural comparison. BMC Med Ethics 14: 25. [Crossref]

20. Ahorlu CK, Bonsu F (2013) Factors affecting TB case detection and treatment in the Sissala East District, Ghana. Journal of Tuberculosis Research. 1: 29-36.

21. Carolyn MF, Angela MB, Robert HG, Dami O (2009) Factors Associated with Delayed Tuberculosis Test-seeking Behavior in the Peruvian Amazon. Am J Trop Med Hyg 81:1097-1102. [Crossref]

22. Ali AOA, Prins HM (2016) Patient knowledge and behavioral factors leading to nonadherence to tuberculosis treatment in Khartoum State, Sudan. Journal of Public Health and Epidemiology 8: 316-325.
23. Waisbord S (2010) Participatory communication for tuberculosis control in prisons in Bolivia, Ecuador, and Paraguay. Rev Panam Salud Publica 27: 168-174. [Crossref]

24. Ibrahim LM, Hadejia IS, Nguku1 P, Lakda GM, et al. (2014) Health care workers' knowledge and attitude towards TB patients under Direct Observation of Treatment in Plateau state Nigeria. PAMJ 18: 1-8. [Crossref]

25. Nyi NN, Catherine D, Abdul Rahman I, Rosemi S (2001) Factors Contributing to Poo Compliance with Anti-TB Treatment among Tuberculosis Patients. South East Asian J. Trop. Med. Publ. health 32: 369-382. [Crossref]

26. Bristow CC, Podewils LJ, BronnerLE, Bantubani N (2013) TB tracer teams in South Africa: knowledge, practices and challenges of tracing TB patients to improve adherence. BMC Public Health 13:801.

Copyright: (C2018 Ahmed OAA. This is an open-access article distributed under the terms of the Creative Commons Attribution License, which permits unrestricted use, distribution, and reproduction in any medium, provided the original author and source are credited. 